\title{
A feminização persistente na qualificação profissional da enfermagem brasileira*
}

\author{
Marta Júlia Marques Lopes \\ Sandra Maria Cezar Leal ${ }^{* * *}$
}

\begin{abstract}
Resumo
Este artigo tece reflexões sobre o universo sociohistórico do cuidado de saúde na perspectiva da divisão sexual do trabalho. A enfermagem é o campo profissional analisado e espelha a feminização no setor. Nesse sentido, pode-se afirmar que persiste a feminização na enfermagem brasileira, o que pode ser observada tanto na qualificação universitária como nos níveis médio e técnico. A enfermagem no setor da saúde representa o maior contingente de trabalhadoras e trabalhadores, sendo marcada pela seletividade com base em "qualidades" de sexo.
\end{abstract}

Palavras-chave: Enfermagem, Feminização, Divisão Sexual do Trabalho.

* Recebido para publicação em janeiro de 2005, aceito em março de 2005.

** Marta Júlia Marques Lopes é professora da Escola de Enfermagem da UFRGS, Sandra Maria Cezar Leal é professora da UNISINOS e enfermeira do HPS / POA / RS, Porto Alegre - RS, Brasil. marta@enf.ufrgs.br

cadernos pagu (24), janeiro-junho de 2005, pp.105-125. 
A feminização persistente

\author{
The Persistent Feminization in Brazil's \\ Professional Nursing Education
}

\begin{abstract}
This article reflects on the socio-historical universe of healthcare under the perspective of the sexual division of labour. Nursing is the professional field analysed, and it mirrors the industry's feminization. In this sense, one can say that feminization persists in Brazilian nursing, which can be seen both in university-level and in secondary and technical schooling. In the health segment nursing represents the largest contingent of workers, marked by selectivity based on gender-related "qualities".
\end{abstract}

Key-words: Nursing, Feminization, Sexual Division of Labour. 
Marta Júlia Marques Lopes

Sandra Maria Cezar Leal

\section{Introdução}

Este artigo tece reflexões sobre a enfermagem como campo profissional na perspectiva da divisão sexual do trabalho. Responde, também, a uma solicitação de Maria Lucia Mott para o dossiê sobre profissionais de saúde e gênero. Portanto, analisamse os contingentes de trabalhadoras e trabalhadores que compõem o campo de ação do cuidado de saúde, conjunto de profissionais denominados equipe de enfermagem, constituído, hoje, por trabalhadores qualificados em três níveis de formação: Enfermeiro $^{1}$, com formação superior no sistema educacional universitário; Técnico de Enfermagem, com formação correspondente ao ensino médio; e Auxiliar de Enfermagem, com função assistencial e em processo de (re)qualificação para o nível técnico.

Parte-se, portanto, de uma breve contextualização assentada na sociohistória da profissão. Apresentam-se, posteriormente, alguns dados que evidenciam tendências na composição da categoria profissional, focalizando os que permitam que se elabore um panorama completo, longitudinal, que reflete contingentes de sexo.

Salienta-se que não existem dados e estudos atualizados centrados nos quantitativos profissionais que permitam aprofundar reflexões sobre aspectos complexos das dinâmicas profissionais $e$ de mudanças ocorridas nos últimos anos. Para traçar o perfil "sexo-demográfico" utilizam-se dados numéricos ${ }^{2}$ disponíveis no Conselho Federal de Enfermagem, órgão de fiscalização do exercício e de associação compulsória. Nesse sentido, apontam-se

\footnotetext{
1 Mantém-se no masculino, pois corresponde a denominação formal do profissional.

2 Conselho Federal de EnfERmagem. Registro quantitativo de profissionais de enfermagem brasileiros, quanto à categoria profissional e o sexo no período de 1990 a 2003. Dados fornecidos por e-mail: cofen@corp.cofen.com.br, 06 de agosto de 2004.
} 
A feminização persistente

algumas tendências, associando algumas reflexões qualitativas advindas de estudos pontuais. Os artigos e dados disponíveis relativos à quantidade de trabalhadoras e trabalhadores raramente problematizam na perspectiva do gênero, limitando-se, na maioria das vezes, a estatísticas por categorias de sexo. Nesse caminho, pretende-se construir algumas reflexões de gênero, ou seja, buscase pensar os números atuais nas diferentes categorias da enfermagem na perspectiva dos atrativos, atributos e qualidades de sexo para o exercício profissional da enfermagem.

Os dados obtidos mostram índices numéricos da composição por sexo das diferentes subcategorias da enfermagem, nos últimos 13 anos (1990 a 2003), utilizados, aqui, para compor o universo de sexo da profissão. A essas limitações, aliam-se algumas reflexões incorporando noções que permitem, mesmo que de forma parcial, discutir sobre alguns elementos dessa realidade.

\section{O universo sociohistórico do cuidado de saúde}

Partindo do processo de feminização da enfermagem como fato histórico, pode-se associar o cuidado de saúde aos processos de reorganização técnica, administrativa e política das instituições de saúde, particularmente hospitalares. É a disciplina imposta aos corpos pelo conhecimento científico, representado pelo saber médico-biologicita, que estrutura e consolida, historicamente, a reorganização das práticas terapêuticas.

Convém salientar que não aprofundamos reflexões de base histórica, entretanto, referenciamos alguns trabalhos de base sociohistórica, centralizando nossas análises na organização dos modelos institucionais das práticas terapêuticas. Nesse sentido, mesmo que as práticas de cuidado à saúde tenham se inspirado, no Brasil, em costumes indígenas e populares, sua institucionalização e profissionalização se fundam, antes de tudo, sob influência da Europa do século XIX. Portanto, mesmo que admitamos, por exemplo, que as construções das identidades 
Marta Júlia Marques Lopes Sandra Maria Cezar Leal

masculinas e femininas no trabalho são móveis e variam no tempo e no espaço, é fato analisado por diferentes estudiosos a indução do processo de institucionalização capitalista do trabalho na saúde à seletividade de um tipo ideal de cuidadora. Assim, as práticas masculinas no cuidado hospitalar até então existentes, mesmo que condicionadas, quase que exclusivamente, ao cuidado de homens doentes ou doentes mentais, são gradualmente substituídas pelas práticas de cuidado exercidas por mulheres leigas, adequadas ao novo perfil exigido, e ideais do ponto de vista das qualidades de sexo. ${ }^{3}$

Retomando aspectos sociohistóricos, podemos dizer que a enfermagem nasce como um serviço organizado pela instituição das ordens sacras. Coexiste com o cuidado doméstico às crianças, aos doentes e aos velhos, associado à figura da mulher-mãe que desde sempre foi curandeira e detentora de um saber informal de práticas de saúde, transmitido de mulher para mulher. É a condenação desses saberes, especialmente para o controle social e religioso da sexualidade e da reprodução, que impõe questionamentos a sua legitimidade e mudanças no seu livre exercício. A marca das ordens religiosas impõe à enfermagem, por longo período, seu exercício institucional exclusivo e ou majoritariamente feminino e caritativo. $O$ tardio processo de

3 Collière, Marie-Françoise. Promouvoir la vie: de la pratique de femmes soignantes aux soins infirmiers. Paris, Inter Editions, 1982; COLLIÈRE, MarieFrançoise e DIEBOLT, Evelyne. Pour une histoire dês soina et professions soignantes. Lyon, AMIEC, cahier 10, 1988; EHNENREICH, Barbara. Witches, Midwives, and Nurses: A History of Women Healers, United States by the Feminist Press. New York, SUNY/College at Old Westbury, 1973, pp.1-43; EHNENREICH, Bárbara e ENGLISH, Deidre. Dolências y trastornos: política sexual de la enfermedad. Cuadernos Inacabados, Barcelona, Ediciones de les Dones, 1984, pp.40-89; KNIBIEHLER, Yvonne. Cornettes et blouses blanches: les infirmières dans la société française, 1880-1980. Rangis, Hachette, 1984; NigTHINGALE, Florence. Notes on Nursing: What it is, and What it is Not. London, J.B. Lippincott, 1946; MolinA, Teresa M. Historia da la enfermeria. Buenos Aires, Intermédica, 1973; PAIXÃO, Walesca. História da enfermagem. Rio de Janeiro, Julio C. Reis, 1979; LOPES, Marta Julia. Les soins: images et realités - o quotidien soignant au Brésil. Thèse de Doctorat, Université de Paris VII, Paris, 1993. 
A feminização persistente

profissionalização atesta essas características e reproduz as relações de trabalho sob o peso hegemônico da medicina "masculina". Assim, a seletividade sexual, assentada em valores ideológicos religiosos, associa-se à seleção de grupos sociais a serem incorporados aos sistemas organizados de saúde em expansão, a partir dos avanços técnicos e tecnológicos do campo científico e da organização capitalista do trabalho.

Pode-se afirmar que são as descobertas microbiológicas e os inúmeros procedimentos técnicos advindos das ciências biológicas e da medicina, aliados a um período de profundas alterações nas relações de trabalho (revolução industrial), que consolidam o campo de trabalho da enfermagem. Nesse sentido, a divisão sexual do trabalho assenta-se em uma tipologia de trabalhador/trabalhadora. Portanto, é a noção de cuidado (de saúde à família), enquanto ação concebida como feminina $e$ produto das "qualidades naturais" das mulheres, que fornece atributos e coerência ao seu exercício no espaço formal das relações de trabalho na saúde. Esse último, historicamente limitado pelas possibilidades sociais das mulheres, pelas perseguições religiosas e pelas corporações médicas. Nessa perspectiva, os valores simbólicos e vocacionais, introduzidos no recrutamento de trabalhadoras, apelam para a entrada seletiva das mulheres nesse espaço profissional apropriado cultural $e$ socialmente ao seu sexo. ${ }^{4} \mathrm{Na}$ compreensão desse processo é necessário considerar a influência de Florence Nightingale ao institucionalizar, na Inglaterra Vitoriana (1862), uma profissão para as mulheres, para a qual elas são "naturalmente preparadas", a partir de valores que se consideravam femininos. Ao longo do processo de profissionalização, esses valores e atributos serão diferentemente explorados no trabalho institucionalizado.

${ }^{4}$ LOPES, Marta Julia. O sexo do hospital. In: LOPES, Marta Julia; MEYER, Dagmar Estermann; WALDOW, Vera Regina. (orgs.). Gênero e Saúde. Porto Alegre, Artes Médicas, 1996, pp.77-105. 
Marta Júlia Marques Lopes

Sandra Maria Cezar Leal

\section{A divisão sexual do trabalho e a enfermagem}

Ao admitir-se que a divisão sexual do trabalho é um princípio organizador da produção capitalista, e que essas formas de organização não são neutras ou somente científicas (e a saúde centra-se nessa cientificidade "neutra"), que são sexuadas e se embasam em uma relação entre os sexos, existente nas sociedades humanas, pode-se assumir alguns pressupostos conceituais na análise da enfermagem.

Assim, a constatação de que essa divisão do trabalho vale para todas as sociedades, mas que suas modalidades variam (o que é trabalho de homem e o que é trabalho de mulher), no tempo e no espaço, não é um fato novo. Esse fato, historicamente evidenciado, nos confronta com a construção móvel das identidades no trabalho, baseadas nas qualidades de sexo e com o fato de que os atributos de uns e de outros (homens e mulheres) estão submetidos a diferentes modos e pólos de atração nesse campo.

Refletir sobre a especificidade da divisão sexual do trabalho nos coloca frente ao fato de que essas diferentes modalidades não põem fim à organização das sociedades em torno da divisão do trabalho entre os sexos, e que essa forma de divisão social do trabalho se articula por interpenetração com outras formas de divisão social.

Ao se transpor essa reflexão para o trabalho da enfermagem, depara-se com a fragilidade da argumentação da relação "cuidado - ação feminina" e da "relação de serviço" como características constitutivas da inclinação das mulheres para determinados setores. Os argumentos que definem os trabalhos de relações humanas como leves e adaptados à fragilidade das mulheres e suas experiências domésticas, proibindo o seu trabalho noturno, tornam-se relativos quando a "necessidade obriga" - por exemplo, os doentes não podem ficar sozinhos à noite no hospital. As exceções se instalam e desaparecem as "fragilidades" $e$, com 
A feminização persistente

isso, as mulheres podem fazer tudo, cabendo-lhes "se arranjarem" com as atribuições familiares.

Portanto, as esferas produtiva e reprodutiva se interpenetram, se entrecruzam, na definição da situação (tempo, espaço, qualidades) do trabalho feminino. É preciso então considerar essas inter-relações e superposições de uma esfera sobre a outra, pois são elas que colorem as experiências (as práticas), sobretudo as femininas.

A partir dessas reflexões, retoma-se a idéia do "natural" para explicar a longa e inquestionável dicotomia trabalho-dehomem / trabalho-de-mulher, e os cuidados de saúde constituem um bom exemplo para esse exercício.

A relação que existe entre as práticas médicas (tratamento) $e$ as da enfermagem (cuidado) traduz, por exemplo, as ligações que existem entre natureza e legitimidade, entre gênero, classe $e$ poder. A (re)construção cotidiana do poder médico $e$ a dominação que exercem as práticas do tratar sobre as práticas do cuidar se articulam na dupla conjunção entre sexo e classe. Esta conjunção define os conteúdos das primeiras - masculinas, científicas, portadoras de valores de verdadeira qualificação profissional - frente às segundas - associadas às "qualidades" femininas, empíricas, etc. Assim, se constituem os espaços que são caracteristicamente aqueles dos experts, do trabalho valorizado, científico, profissional, e os de suporte (mesmo que indispensáveis) massivos, rotineiros, taylorizados, exigentes em presença constante (24 horas), intensivos e também ditos de hotelaria. Desta forma, no espaço social e, particularmente, no campo da saúde, esses agentes ocupam territórios diferentes. $\mathrm{O}$ diagnóstico e a terapêutica médica representam os atos-fim, o saber que embasa a organização e os processos de trabalho na saúde. Os atos médicos são concretos, quantificáveis, justificam maior salário e pagamento por ato realizado. Isso nos confronta com a visibilidade do trabalho médico, enquanto que o trabalho de enfermagem, por sua vez, se incorpora aos fins, se invisibiliza. Sua existência concreta se materializa nas jornadas contínuas, nas 
Marta Júlia Marques Lopes Sandra Maria Cezar Leal

24 horas de presença no hospital, por exemplo, que exprimem a intensividade do trabalho e sua indispensabilidade. No entanto, sua concepção enquanto savoir-faire feminino, baseado em um sistema de qualidades o dessingulariza e subsidiariza sua ação, inscrevendo-a em uma dinâmica móvel de divisão do trabalho $e$ de processos de trabalho, ditados, em parte, pelo saber médico, mas também pela gestão organizacional da saúde. Eis que essas concepções e a qualificação (competências e valores) definidas pelo empregador (os serviços e a prática médica), sustentam, de um lado, a hierarquia e os baixos níveis salariais da enfermagem $e$, de outro, os postos mais valorizados nesse aspecto $e$ na estrutura de poder.

Portanto, diferentes esferas de competência, visíveis entre o tratar e o cuidar, repousam na hierarquia social homem-mulher. Nesse sentido é importante ressaltar que o caráter sexuado das práticas formais e ou informais de saúde e sua hierarquização não resultam unicamente do fato de que elas se vinculam ao exercício da medicina, mas também de que elas fazem parte de um sistema mais geral que associa o sexo (gênero) e classe social para confortar o poder masculino.

Enfim, nesse contexto, pode-se afirmar que a enfermagem permitiu e facilitou aos médicos o exercício da medicina tal qual a conhecemos. Por exemplo, se nos referimos à noção de higiene, constatamos que a mesma ilustra a mobilidade e a hierarquização das duas práticas. Enquanto noção científica, a higiene colocou em cena princípios como os de anti-sepsia, assepsia e proteção imunológica, mas serviu, paralelamente, para justificar a profissionalização de auxiliares para a medicina. Na passagem de noção constitutiva para a de qualidade e ou qualificação de mulheres, a higiene perdeu sua cientificidade, o caráter "higienizante" dessa ação se associando ao de prática doméstica. Tornou-se, portanto, o traço identificador das tarefas das quais se incumbe a enfermagem e que são simbolizadas por instrumentos próprios do cotidiano doméstico: a vassoura, a bacia, o urinol, entre outros. Mesmo se esfregar e limpar ganharam novas 
A feminização persistente

dimensões no espaço dos serviços de saúde e do hospital em particular, o valor social de tais atos não foi modificado. No entanto, a higienização constitui um dos componentes essenciais do cuidado de saúde. Os cuidados com a higiene se materializam em ações fundamentais ao processo terapêutico, na medida em que respondem as necessidades básicas de manutenção da vida $e$ recuperação do bem-estar. O que queremos mostrar é que o fato de se associar (funcionalmente) essas práticas no campo do trabalho, sobretudo hospitalar, às "qualidades" (e não qualificação) femininas condena essas ações ao status de tarefas intermediárias, destituídas de valor científico no processo terapêutico. Não é sua indispensabilidade no processo terapêutico que preside a organização da hierarquia e dos espaços de exercício das práticas de enfermagem e das práticas terapêuticas no sentido amplo, mas sua definição enquanto ação de enfermagem, ação feminina. Portanto, assiste-se gradativamente, sobretudo no domínio da higienização e da anti-sepsia hospitalar, a uma seletividade hierarquizada de tarefas. Esta seleção não se baseia em seu valor assistencial ou terapêutico, ou mesmo na integralidade do paciente, mas no "prestígio" social dos seus protagonistas, na perspectiva de classe e sexo. Enfim, limitamonos a ilustrar esse aspecto neste texto, poderíamos, entretanto, desenvolver outros que configuram o universo do trabalho na saúde e suas práticas institucionais.

Avançando nas reflexões, a enfermagem e as enfermeiras não são mulheres na sua maioria por acaso. Tanto quanto a situação feminina, em sentido amplo, a enfermagem, as enfermeiras e os enfermeiros são produtos de uma construção complexa e dinâmica da definição de "ser" da enfermagem e das relações entre os sexos. Os valores simbólicos e vocacionais são um exemplo de concepção de trabalho feminino baseada em um sistema de qualidades, ditas naturais, que persistem a influenciar o recrutamento majoritariamente feminino da área.

A predominância feminina no cuidado e na enfermagem faz com que ainda se identifique um discurso homogêneo em relação 
Marta Júlia Marques Lopes Sandra Maria Cezar Leal

ao sexo. A despeito de algum grau de masculinização, não se pode falar em concorrência e rivalidades de sexo no interior da enfermagem. No discurso interno, afirma-se em estudos anteriores $^{5}$, que a enfermagem não deprecia as práticas masculinas e, no interior da equipe, é difícil identificar efeitos de condutas de competição entre os sexos. Observa-se, também, a permanência de certos símbolos e situações que atestam que a profissão não é valorizante para a imagem social masculina. No caso dos homens, a sustentação do seu recrutamento no mercado de trabalho não raro apela para os atributos e qualidades naturais masculinas, como a força física (da mesma forma que para os femininos: como dedicação e paciência), sem considerar formação e/ou qualificação para o trabalho.

\section{Os contingentes de sexo na atualidade}

Em relação aos contingentes de sexo na profissão, em estudo realizado em $1987^{6}$, constatou-se a predominância feminina em todas as categorias de trabalhadores de enfermagem. Nesse período, os índices apontavam um grau de feminização entre os enfermeiros de $94,1 \%$; entre os técnicos de enfermagem esse índice baixa para $89 \%$, e entre os auxiliares de enfermagem os percentuais apontam $91,5 \%$ de feminização .

\footnotetext{
${ }^{5}$ LOPES, Marta Julia Marques. O trabalho da enfermeira: nem público, nem privado - feminino, doméstico, desvalorizado. Dissertação de Mestrado, Sociologia, Pontifícia Universidade Católica, Porto Alegre, 1987 e LOPES, Marta Julia Marques. Divisão do trabalho e relações sociais de sexo: pensando a realidade dos trabalhadores do cuidado da saúde. In: LOPES, M. J. et alii (org.) Gênero e Saúde. Porto Alegre, Artes Médicas, 1996. pp.55-62

6 ID. O trabalho da enfermeira... Op. cit.

7 ID., IB.
} 
GRÁFICO 1: Trabalhadores de enfermagem do sexo masculino, por categorias, no período de 1990 a 2003, Brasil, 2004

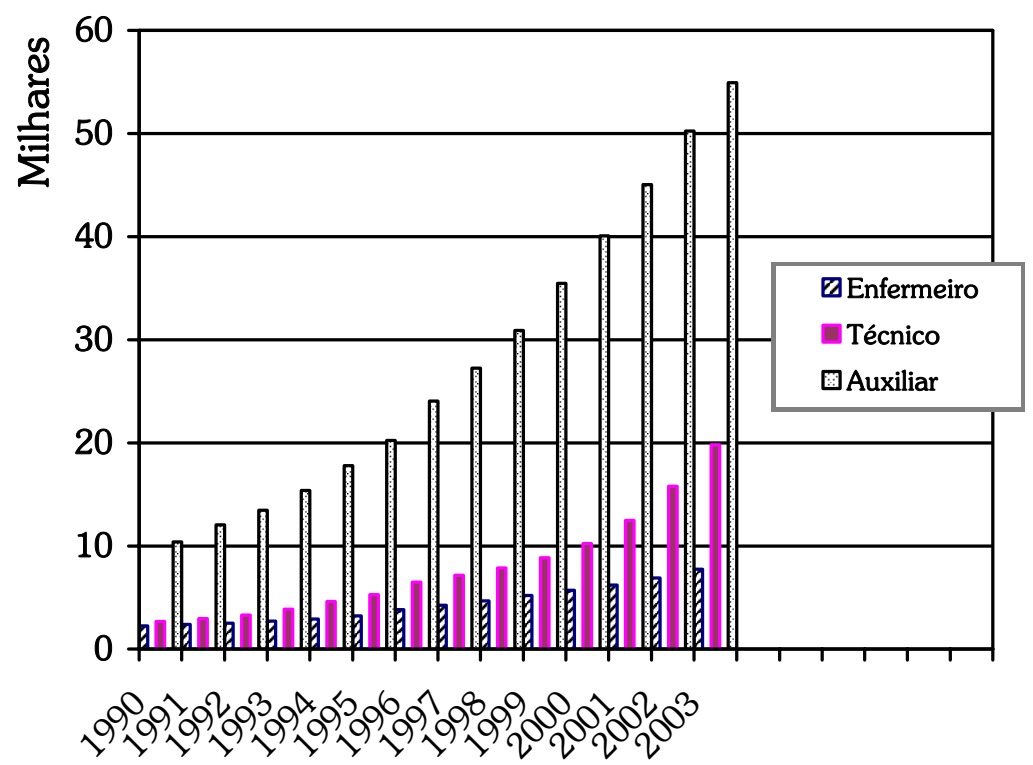

Fonte: dados primários COFEN, elaborado pelas autoras, Porto Alegre, 2004.

Atualmente, esses índices, que podem ser observados nos gráficos 1 e 2 e em trabalhos acadêmicos recentes ${ }^{8}$, atestam, por exemplo, que o aumento de homens na profissão é gradual e estável, o que se deve, sobretudo, à "segurança, estabilidade e

8 Pereira, Álvaro. O quotidiano profissional do enfermeiro: das aparências às diferenças de gênero. Tese de Doutorado, Enfermagem, UFSC, Florianópolis, 1999. FILIPON, Jonathan Gonçalves. Homens cuidadores: escritos selecionados. Monografia de Conclusão de Curso. Escola de Enfermagem, UFRGS, Porto Alegre, 2004. 
Marta Júlia Marques Lopes Sandra Maria Cezar Leal

garantias" de postos de trabalho que a área oferece. Esse argumento encontra sua maior expressão entre auxiliares $e$ técnicos de enfermagem, parcela da população de trabalhadores que é advinda de extratos socioeconômicos mais baixos.

GRÁFICO 2: Trabalhadoras de enfermagem do sexo feminino, por categorias, no período de 1990 a 2003, Brasil, 2004.
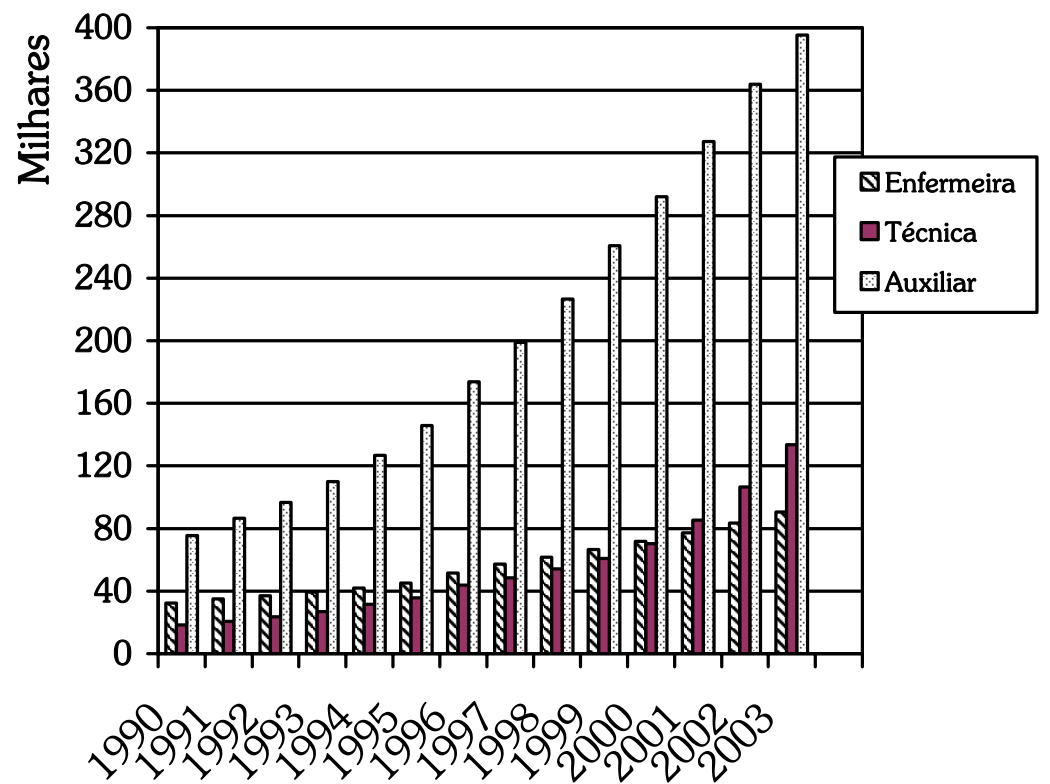

Fonte: dados primários COFEN, elaborado pelas autoras, Porto Alegre, 2004.

Os gráficos 1 e 2 evidenciam a evolução dos quantitativos em relação às categorias, sendo possível, também, identificar a 
A feminização persistente

estabilidade em relação ao sexo, com a predominância feminina em todas as categorias.

Vale ressaltar que em decorrência da Lei do Exercício Profissional 7498/869, a partir de 1996 observa-se um aumento significativo, em ambos os sexos, no quantitativo da categoria de auxiliares de enfermagem. A Lei estipulou o prazo de dez anos (até o ano de 1996) para a qualificação dos profissionais não incluídos na categoria como: atendentes de enfermagem, auxiliares de serviços médicos e hospitalares, entre outros. Muitos optaram pelo curso de auxiliar de enfermagem.

Analisando-se a formação superior atual e comparando-a com a da década de 1980, observa-se que o percentual evolui de $5,9 \%$ homens, nessa categoria, para $7,9 \%$ vinte anos depois. Considerando-se esses $2 \%$, constata-se que é baixa a inserção de homens no mercado de trabalho do cuidado de saúde, sobretudo se considerarmos que, no final da década de 1980 existiam menos de 100 cursos de enfermagem nas universidades brasileiras e que, atualmente, existem 450, concentrados, sobretudo, na região sudeste. ${ }^{10}$ Houve um aumento na ordem de $159 \%$ dos cursos universitários, considerando-se o ano de 2000 em diante. Portanto, o atrativo da formação universitária não é apelo suficiente para que os homens vislumbrem na enfermagem uma verdadeira e valorizadora opção profissional.

Estudos populacionais sobre qualificação e emprego apontam para a tendência de jovens de camadas mais pobres a procurarem o ramo dos serviços pela perspectiva de entrada mais rápida no mercado de trabalho e pelo crescimento de oportunidades. Acredita-se que esse fator é mais influente na inserção, mesmo que pequena $e$ lenta, de homens na

9 AsSOCIAÇÃo BRASILEIRA DE ENFERMAGEM. A "nova" lei do exercício profissional da enfermagem. Cadernos de Legislação - Documentos I. Brasília, ABEn, 1987.

${ }^{10}$ BRASIL. Ministério da Educação. Instituto Nacional de Estudos e Pesquisas Educacionais Aloísio Teixeira (INEP). Pesquisa realizada no site sobre o número de Cursos de Enfermagem em Instituições de Nível Superior no Brasil. Disponível em: http://www.inep.gov.br. Acesso: 15 de agosto de 2004. 
Marta Júlia Marques Lopes Sandra Maria Cezar Leal

enfermagem, particularmente nas categorias de auxiliares $e$ técnicos, do que uma tendência reveladora de mudança nas opções masculinas, atrativos profissionais técnico-científicos ou, ainda, de ascensão econômica (para o nível universitário).

Estudo envolvendo auxiliares de enfermagem em exercício hospitalar ${ }^{11}$, afirma que persiste a resistência na aceitação da escolha profissional por parte de familiares e amigos. Diz a autora que esta resistência é menor entre aqueles oriundos de estratos socioeconômicos desfavorecidos, o que os leva a considerarem o acesso a área uma forma de ascensão social.

Já os argumentos ou "qualidades naturais" masculinas para o trabalho permanecem aqueles relacionados ao uso da força física. Esses argumentos são sustentados pelos próprios trabalhadores que vêem nesses atributos o fortalecimento de sua condição de homens e a garantia do exercício de tarefas ou atividades exclusivas a esses atributos. Também são evidenciadas condutas que atestam que, entre os poucos homens da enfermagem, uma espécie de solidariedade de gênero se estabelece na relação com os médicos homens e a sua visibilidade e competência se vê fortalecida pela condição de minoria. $\mathrm{O}$ exercício de ações de cuidado de forma seletiva, baseadas no sexo dos pacientes, por exemplo, aparece como uma espécie de segregação que os condiciona ainda mais "às tarefas possíveis" $e$ aceitas pelo sujeito cuidado. Se, no caso dos médicos, a submissão ao saber $e$ às práticas terapêuticas da medicina não se configura em barreiras para o exercício dos homens, no caso da enfermagem existe essa resistência. A medicina, enquanto prática terapêutica, não tem sexo; a enfermagem, enquanto prática do cuidado, tem apenas um sexo no imaginário social - o feminino. Homens cuidando e desempenhando práticas com o corpo biológico (mais próximos às práticas domésticas, maternas, de

${ }^{11}$ WAINBERG, Sara. Experiências e vivências de auxiliares de enfermagem do sexo masculino no exercício de uma profissão majoritariamente feminina. Dissertação de Mestrado, Psicologia, Instituto de Psicologia, UFRGS, Porto Alegre, 2004 
A feminização persistente

cuidado e higienização) não são homens ou são menos valorizados socialmente.

Existem, portanto, articulações entre as categorias gênero $e$ trabalho na enfermagem expressas na segregação por atividades e por especialidades da área. A falta de estudos mais abrangentes, neste momento, não permite que se discuta quais são essas áreas de concentração e preferência. No entanto, essa constatação está presente em estudos de caso anteriores, por exemplo, em "O sexo no Hospital", publicado em $1996 .{ }^{12}$ Assim, a prática evidencia que existe uma seletividade induzida pelo mercado de trabalho que se baseia no tipo de necessidades assistenciais definidas, por sua vez, pela medicina no campo da assistência individual e pelo aparato técnico e tecnológico empregado na terapêutica. Existem áreas que, tradicionalmente, concentram maior número de mão-de-obra masculina, como a assistência psiquiátrica, a ortopedia, os serviços radiológicos, entre outros. Essa tradição segue as características das práticas terapêuticas vinculadas ao uso da força física e baseadas na noção de risco técnico. Executar atos de contenção, tracionar, irradiar, são verbos conjugados nos processos de trabalho da enfermagem nesses setores. Nessa perspectiva, Kergoat ${ }^{13}$ afirma que é baseada na força física que repousa a lógica social das práticas masculinas no cuidado de saúde.

Em estudo do Ministério da Saúde, em 2000, sobre o perfil de médicos e enfermeiros no Programa de Saúde da Família (PSF), pode-se observar que a saúde pública (predominantemente trabalho assalariado) é um espaço de concentração de trabalho feminino. Mesmo que a medicina no Brasil seja ainda predominantemente masculina $-67,3 \%$ para $32,7 \%$ de mulheres no PSF o número de mulheres médicas é proporcionalmente maior $(44,05 \%)$. No entanto, o número geral de profissionais é

\footnotetext{
${ }^{12}$ LOPES, M. J. M. O sexo no ... Op. cit.

${ }^{13}$ KengoAt, D. Da divisão do trabalho entre os sexos. Paris, Gedisst, texto apresentado no Seminário Tecnologias, Processos de Trabalho e Políticas de Emprego. São Paulo, Curso de Pós-Graduação em Sociologia, USP, 1987.
} 
Marta Júlia Marques Lopes Sandra Maria Cezar Leal

predominantemente feminino. A enfermagem, nesse programa institucional, compõe-se de $90,91 \%$ de mulheres, índice próximo aos percentuais entre os enfermeiros diplomados. ${ }^{14}$ Outros argumentos atestam a procura seletiva pelas profissões representando diferenciais importantes, tanto no que diz respeito a categorias socioeconômicas, quanto ao que se denomina "linhagem familiar". Para a medicina, a linhagem médica, ou seja, a presença de familiares médicos ocorre em $62,09 \%$ dos casos. Para a enfermagem, essa condição é observada somente em $19,11 \%$ dos casos, enquanto que o percentual de enfermeiros com parentes médicos é o dobro. ${ }^{15}$

Esses aspectos caracterizam as expectativas de classe e sexo no âmbito das escolhas profissionais no nível superior de escolaridade. Pode-se argumentar, também, com base nas diferenças de renda e salariais que, mesmo na condição de assalariados, enfermeiros e médicos têm rendimentos diferenciados. O estudo do Ministério da Saúde ${ }^{16}$ atesta que, em nível nacional, os médicos têm uma renda, em média, de 2.229 dólares, enquanto que para o enfermeiro a média é de 1.123 dólares. A própria expectativa de ascensão salarial é comparativamente mais elevada no caso dos médicos. Não se duvida, com essas disparidades, que as perspectivas econômicas e valorizantes do ponto de vista do ideal masculino influencie nas escolhas profissionais. $\mathrm{O}$ trabalho assalariado tem sido a principal forma de inserção da enfermagem e dos enfermeiros no exercício profissional, e isso representa também um diferencial comparativo com a prática médica, pois o trabalho autônomo (liberal) e a prática de consultório são freqüentes enquanto processo e relações de trabalho no exercício da medicina.

${ }^{14}$ Brasil. Ministério da Saúde. Perfil dos Médicos e Enfermeiros do Programa Saúde da Família no Brasil. 2000. Disponível em: http://www.ensp.fiocruz.br/psfperfil/prefacio.html. Acesso: 14 julho 2004.

${ }^{15}$ ID.; MACHADO, Maria Helena. Os Médicos no Brasil: um retrato da realidade. Rio de Janeiro, FIOCRUZ, 1997.

${ }^{16}$ BrasiL, M. S. Perfil dos Médicos... Op. cit. 
A feminização persistente

\section{A qualificação acadêmica entre enfermeiros e enfermeiras}

Com base no catálogo de Informações sobre Pesquisas e Pesquisadores em Enfermagem no Brasil ${ }^{17}$ - elaborado a partir dos Programas de Pós-Graduação de mestrado e doutorado dentre as 3524 dissertações e teses catalogadas até o ano de 2003 $e$ em condições de serem identificadas pelo sexo do autor, encontrou-se 3248 sendo 5,08\% de enfermeiros e 94,92\% de enfermeiras. Essa situação permite afirmar que a inserção de homens nos programas de Pós-Graduação Stricto Sensu apresenta pequena desvantagem em relação às mulheres. Considera-se que a busca pela qualificação acadêmica está relacionada ao prestígio do professor de carreira universitária a qual representa ascensão profissional. A participação de homens na docência de nível médio e superior merece uma investigação mais criteriosa, já que nem todos os professores enfermeiros, mesmo em exercício no ensino superior, são titulados no sistema de Pós-Graduação Stricto Sensu.

\footnotetext{
${ }^{17}$ Associação Brasileira de Enfermagem. Centro de Estudos e Pesquisas em Enfermagem - 1979/2000: Informaçôes sobre pesquisas e pesquisadores em enfermagem. ABEn, Brasília, vol. 1, n 18, 2001; CD-ROM AsSOCIAÇÃo BRASILEIRA DE Enfermagem. Centro de Estudos e Pesquisas em Enfermagem - 2001: Informações sobre pesquisas e pesquisadores em enfermagem. ABEn, Brasília, vol. XIX, 2001; AssociaÇão Brasileira DE EnfERmagem. Centro de Estudos e Pesquisas em Enfermagem - 2002: Informaçôes sobre pesquisas e pesquisadores em enfermagem. ABEn, Brasília, vol. XX, 2002. Disponível em: http://www.abennacional.org.br/documentos/ tituloscatalogoxx.pdf. Acesso: $10 \mathrm{de}$ dezembro 2004; AssociaÇão Brasileira de EnfERmagem. Centro de Estudos e Pesquisas em Enfermagem - 2002: Informações sobre pesquisas e pesquisadores em enfermagem. ABEn, Brasília, vol. XXI, 2003. Disponível em: http://www.abennacional.org.br/documentos/Catalogo2002\%20Segundo\%20Se mestre.doc. Acesso: 10 de dezembro 2004; AsSOCIAÇÃO BRASILEIRA DE Enfermagem. Centro de Estudos e Pesquisas em Enfermagem - 2003 Informações sobre pesquisas e pesquisadores em enfermagem. ABEn, Brasília vol. XXII, 2004. Disponível em: http://www.abennacional.org.br/documentos/ Cat\%E1logo\%20CEPEn\%202003\%20040504.pdf. Acesso: 10 de dezembro 2004.
} 
Marta Júlia Marques Lopes

Sandra Maria Cezar Leal

A representatividade de homens e mulheres nos órgão de classe

A Associação Brasileira de Enfermagem (ABEn) e o Conselho Federal de Enfermagem (COFEN) são os órgãos de classe que agregam todos os profissionais de enfermagem (auxiliares, técnicos e enfermeiros). A ABEn foi fundada em 1926 e até $\mathrm{O}$ ano de 2004 a presidência da Associação sempre foi exercida por mulheres, mesmo se a partir da década de 1950 alguns homens começaram a integrar a diretoria. Pode-se afirmar que a $\mathrm{ABEn}$ é representada historicamente por mulheres, tendo marcado significativamente a trajetória técnica, política e ideológica da categoria. ${ }^{18}$

Outra instituição representativa é o Conselho Federal de Enfermagem (COFEN) criado em 1973, de associação compulsória, que regulamenta o exercício da profissão no Brasil. A presidência do Conselho foi exercida por mulheres até o ano de 1990. Nos períodos de 1990 a 1997 e de 2000 até o ano atual a presidência da entidade tem sido exercida por um enfermeiro que se mantém no poder e marca suas gestões com a publicação de um livro intitulado "O homem de um século". ${ }^{19}$ Neste caso, evidencia-se a posição de poder masculino compatível com a natureza da instituição caracterizada pelo controle e fiscalização do exercício da profissão.

No que diz respeito aos sindicatos, a partir de informações orais de dirigentes, identifica-se que as representações diretivas dessas entidades são mais atrativas aos homens, sendo evidenciado pelo número deles que, nos últimos anos, ocuparam a presidência, como pode ser observado no Sindicato dos

${ }^{18}$ GeRMANO, Raimunda Medeiros. Educação e ideologia da enfermagem no Brasil - 1955/1980: um estudo da Revista Brasileira de Enfermagem. São Paulo, Cortez, 1983.

${ }^{19}$ CONSElho Federal DE Enfermagem. O homem de um século. http:// www.portalcofen.com.br/\%5Fnovoportal/default.asp. Acesso em 9 de dezembro 2004. 
A feminização persistente

Enfermeiros do Rio Grande do Sul. No entanto, não dispomos de informações atuais para as demais entidades no país.

\section{Considerações finais}

Com essas reflexões pode-se afirmar que a profissão se mantém feminina em todos os níveis, a despeito do aumento contingencial. Esta constatação gera a seguinte questão: esta feminização, persistente desde o início da profissionalização, é o resultado de esforços que lhe são exteriores $e$ de interesses preocupados em manter a profissão em uma condição auxiliar, de desvalorização técnica e econômica, ou se está frente a uma profissão de mulheres que se protege? Sob a lógica pela qual a profissionalização se instituiu, conclui-se que se trata de uma profissão "para mulheres" e de mulheres que se protege.

Em princípio, poder-se-ia dizer que existe no meio da enfermagem brasileira uma seletividade deliberada baseada no sexo. Esta seletividade se exprime no ensino, e é condicionada, ideologicamente, por parte das candidatas. Ela é igualmente deliberada no sentido em que marca as preferências do sistema em todos os níveis. Os textos didáticos e a conduta das professoras e professores (mais raros) atestam tal seletividade, que pode ser observada, por exemplo, na seleção dos pacientes $e$ técnicas mais adequadas às habilidades de gênero. A atuação no desenvolvimento de técnicas com recém-nascidos e prematuros é um exemplo prático, pois os estudantes homens reclamam que muitas professoras partem do pressuposto que não têm habilidade para cuidar com destreza, segurança e carinho, visto a fragilidade dos pacientes e os "modos de ser" mais "masculinos".

Os processos de recrutamento, o mercado de trabalho enfim, também atesta essa preferência. Os espaços físicos e os espaços que ocupam as especialidades profissionais no meio hospitalar, particularmente, são evidências dessa concepção sexuada de exercício profissional. A organização hospitalar, na diversidade de qualificações e na complexidade dos processos de 
Marta Júlia Marques Lopes

Sandra Maria Cezar Leal

trabalho que apresenta é, por assim dizer, a expressão mais acabada da divisão social e sexual do trabalho no setor da saúde.

Neste sentido, crê-se que é necessário agregar aos níveis de qualificação e profissionalização femininos e à entrada massiva das mulheres no mercado de trabalho, os argumentos ideológicos de interesse na manutenção da divisão sexual: as relações entre o saber e a manutenção da hegemonia do tratamento sobre o cuidado; as relações entre o poder e a garantia da hierarquia de posições e de postos de decisão e as relações entre os salários; a manutenção das diferenças de remuneração, entre outras, baseadas nas diferenças de concepção da qualificação e valor de trabalho feminino e masculino.

A diversidade das interpretações não esgota as explicações da persistente feminização. Por outra via, menos concreta, poderse-ia dizer que parece se redesenhar a defesa, histórica entre as mulheres, de sua condição de "cuidadoras". Cuidar é, de certa forma, uma ação identitária feminina que transcende o espaço de trabalho. Somente as mulheres aprendem a cuidar, $e$ são principalmente os cuidados de manutenção da vida que alimentam essa justificativa. Elas constroem, em conseqüência, um saber-fazer que se esforçam em valorizar, amar e defender (por que não?) ao longo de suas vidas. 